\title{
Exploration and Reform in Education of Biochemistry for Clinical Medicine
}

\author{
Zhang Jin ${ }^{1}$, WangMeng ${ }^{1}$, Lin $\mathrm{Na}^{1}$, Du Hang ${ }^{1}$ \\ ${ }^{1}$ Binzhou Polytechnic, Binzhou, Shandong 256600, China \\ Email:'zhangjinbz@163.com
}

\begin{abstract}
Biochemistry theory and technology is an important tool to analyze the etiology, development mechanism, diagnosis and treatment of clinical related diseases. It is an important subject in the training and education of clinicians. Based on the related problems in biochemistry teaching practice, such as various contents, difficult understanding, loose combination of theory and practice, and easy separation from the development of science and technology, it is necessary to reform the teaching of biochemistry" The teaching reform of "biochemistry" course should be considered from the aspects of optimizing teaching content, adjusting teaching methods, constructing innovative teaching team and improving evaluation system, so as to provide reference for the improvement of teaching quality of the course, so as to comprehensively improve students' knowledge, skills and innovation ability.

Keywords: biochemistry, clinical medicine, reform in education, innovation
\end{abstract}

\section{INTRODUCTION}

Biochemistry is the study of the chemical composition, structure and function of substances in organisms, as well as various chemical changes in the process of life activities and their relationship with the environment by using the principles and methods of chemistry, physics and biology.The discipline of interrelationship. With the development of research, biochemistry integrates the theory and technology of physiology, cell biology and other disciplines, and has a wide range of contact and intersection with many disciplines. Biochemical theory and technology is an important tool to analyze the etiology, development mechanism, diagnosis and treatment of clinically related diseases, and lay the foundation for the study of follow-up courses such as pathophysiology and immunology[1]. Because of the variety of contents, the difficulty of understanding and memorizing, especially the metabolism part, the complex reaction and mutual connection, "biochemistry" has become a difficult course in the basic courses of medical colleges and universities, and enjoys the reputation of "four famous supplements" in students' examinations. Optimize the teaching content, pay attention to basic knowledge, infiltrate teaching. The biochemistry course of our undergraduate clinical medicine major is in the third semester. The textbook is biochemistry (9th Edition) edited by Zhou Chunyan and Yao Libo. And molecular biology[2]. According to the teaching content and syllabus arrangement,Structure and function of biological macromolecules, material metabolism and its regulation, genetics.Information transmission is the main content of biochemistry class; Medical Biochemistry.Questions such as liver and gallbladder biochemistry, blood biochemistry and so on are closely related to clinical subjects.They are listed in the clinical biochemistry elective course; Main topics of Medical Molecular Biology.In molecular biology class. This arrangement reflects the hierarchical teaching.According to their knowledge, ability and development potential, students can have their own ideas.

Focus on the arrangement. Biochemical experiment course is arranged according to relevant contents elect the chapter of "hypersensitivity reaction" for teaching research, teachers write cases, questions and test questions, complete the students' pre class knowledge test two weeks before class, and then distribute the learning materials; Students were divided into groups, and self-study and discussion were conducted according to the guidance of cases and problems; In class, students are led to study cases and solve problems in groups, and teachers guide and summarize appropriately; Complete the after class test and questionnaire survey.It is a comprehensive and open experiment, especially in molecular biology It is difficult to fully grasp the course content through theoretical explanation. Some open and comprehensive experiments have been carried out, such as PCR amplification and agarose gel electrophoresis detection, electrophoresis separation of proteins, enzyme digestion, linkage and transformation of DNA, so as to cultivate students' enthusiasm for scientific research, enhance students' innovative ability, discover and solve problems, which is very important for future medical treatment or scientific research. 


\subsection{Related Work}

Reform of teaching methods, contact with the reality of life, diversified teaching

Theory teaching adopts diversified teaching mode.Biochemistry is closely related to the reality of life, including health, nutrition, disease and medicine[3]. Therefore, when teaching relevant content, we must pay attention to the combination of theory with practice, design typical teaching cases, put forward relevant problems, inspire students to study and think with problems, and cultivate students' innovative thinking and ability to analyze and solve problems. All the students were tested before class and 11 multiple-choice questions were set; After class, the corresponding knowledge points were tested, and 21 multiple-choice questions were set; Please complete the questionnaire survey of POPs teaching.Statistical analysis. L-test was used to compare the scores of pre class test and after class test between the two groups. The education concept of "student-centered" should be highlighted in learning. The teaching method gradually changes from the traditional and single teacher lecture mode to the problem-based teaching, team based teaching, case-based teaching and a variety of online learning means such as micro class, MOOC and other diversified teaching methods[4]. There are many biochemical contents and it is difficult to understand and remember. In the process of learning, we can combine a variety of teaching modes according to learning ability and learning habits, break the space-time limit, change passive learning into active learning, stimulate learning interest, mobilize learning enthusiasm, and promote the formation of personalized learning methods.

Experimental teaching combines biochemical indexes with clinical cases. Biochemical indexes can reflect people's health status and help to diagnose clinical diseases.Diagnosis and treatment are very important. Through the study of biochemical experiment, we should not only consolidate theoretical knowledge and improve students' operation ability, but also pay attention to the combination of theoretical knowledge and clinical practice, and strengthen the clinical significance of various biochemical indexes. For example, in the biochemical experiment class, the determination of serum protein content, serum protein electrophoresis, arrange students to test their own blood samples, and analyze various indicators after the test, clear the relationship between the changes of serum protein content and types and disease diagnosis, deepen students' understanding of biochemical knowledge, and improve students' interest in learning. Before class and after class, the test results were mainly 2014 and 2015 students, and the questionnaire that failed to complete $100 \%$ of the answers was removed. Finally, the number of participants in the experimental group was 53 before class and 55 after class; The number of participants in the control group was 46 before class and 53 after class; 194 questionnaires were collected from 2013, 2014 and 2017.

\subsection{Our Contribution}

Build innovative teaching team, carry out teaching research, in-depth teaching.It is worth every teacher's thinking and exploration to improve the teaching quality and make students form the learning motivation of "knowing, doing well and enjoying". First of all, biochemical teachers must be familiar with all the contents of biochemical teaching materials. This requires a lot of time to read and study the authoritative biochemical textbooks and summarize the relevant knowledge structure[5]. Secondly, teachers should listen to more experienced teachers and make full use of the high-quality resources on the Internet. Teaching is an art. The explanation of key and difficult knowledge, the combination of theory and clinical cases, and the introduction of new technology development and application reflect a teacher's "deep and shallow skill". Thirdly, biochemistry teachers of clinical medicine should have rich clinical knowledge, pay more attention to the collection of cases and the connection with relevant biochemical knowledge, communicate with clinicians, constantly enrich and improve their knowledge structure, and realize the unity of basic and clinical knowledge. Finally, teachers should have rich scientific research knowledge and meticulous scientific research thinking, guide students to learn new theories and technologies in teaching, and cultivate scientific research thinking and innovation ability. In short, the times are changing and knowledge is updating[6]. Teachers' teaching ideas, teaching contents and teaching means should keep pace with the times. Teachers should think about problems from the perspective of students, teach students in accordance with their aptitude, work hard on the preparation before class, classroom design, teaching skills and teaching means, constantly update the contents, ideas and teaching plans, carry forward the endless teaching artistry, constantly accumulate and innovate in teaching, and integrate teaching in happy country.

\section{BACKGROUND}

It is an important part of classroom teaching activities to improve the evaluation system, pay attention to the process evaluation and promote teaching evaluation. It is the evaluation of the process and results of students' learning and teachers' teaching. In teaching activities, how to evaluate students scientifically, objectively and comprehensively is an important part of giving full play to students' main role. As far as biochemistry course is concerned, there are many knowledge 
points, abstract concepts and complex metabolism, so it is difficult for students to fully understand and memorize the relevant contents. Therefore, in the teaching process, not only summative evaluation should be adopted, but also formative evaluation should be paid attention to, so as to improve the proportion of normal performance. In addition to the final examination, classroom notes, course essays, experimental design, and experimental results can be used as the assessment of students' usual performance, so as to comprehensively examine students' mastery and application of knowledge, ability to analyze and solve problems, and cultivation of innovative thinking.

In short, the times are changing, knowledge is changing, and students are changing. The teaching of biochemical course should keep pace with the times. Under the premise of highlighting "students as the main body", we should constantly adjust and innovate the teaching content, teaching methods, teaching staff, and evaluation system, so as to promote the development of students' learning and education.

In this study, pops teaching is used in medical immunology teaching. It explains the occurrence process and mechanism of symptoms in clinical cases by designing basic knowledge of immunity, so that students can understand the importance of immune knowledge, and thus improve students' interest in learning; In the teaching process, middle school students need to obtain knowledge by reading books and documents themselves, and greatly mobilize the initiative of students' learning while improving their self-study ability; Learning in groups can improve students' logical thinking and expression ability, which are very important for medical professionals. The results of POPs teaching were compared with the traditional teaching, and the results of the pre class test were not significantly different between the two groups, and the knowledge of "hypersensitivity response" was quite good before learning; The results of the post-school test in the experimental group were significantly higher than that of the control group, which indicated that the students who were taught by POPs made greater progress in the knowledge structure after learning. The results of questionnaire survey show that most students think pops improves their self-study ability, learning motivation and understanding and memory of relevant knowledge points, so they all agree with this new teaching method. Some students think this teaching method is not conducive to their more focused in class, and may be related to the students' adaptation to the teaching method.

Although pops teaching method can stimulate students' desire for knowledge, it also faces some problems to overcome: for example, students need to have certain self-study ability, self-control and team cooperation; In addition to having solid theoretical knowledge, teachers should master clinical immunology, so as to design targeted, purposeful and scientific clinical cases around the syllabus, and help stimulate students' enthusiasm for study; The teaching reform requires teachers and students to make a lot of preparations in the early stage, so as to achieve good teaching results. In the future, further research will be done on these problems, aiming to stimulate students' innovation and thinking ability better, and improve teaching quality and teaching effect.

\section{CONCLUSION}

In recent years, with the rapid development of medical science, the knowledge of medical immunology is updated rapidly, the theory is strong, and the content is abstract, Cultivate students' ability of independent exploration and learning, and mobilize students' learning enthusiasm. Compared with the traditional teaching method, it can embody the teaching idea of "student-centered". [7]By observing the test results before and after the implementation of POPs teaching, students' teaching feedback, combined with teachers' teaching observation and reflection, this paper evaluates the effect of traditional teaching and pops teaching, in order to put forward a better teaching scheme for the teaching method reform of medical immunology and improve the teaching quality.

\section{REFERENCES}

[1] Zhou Chunyan, Yao Libo. Biochemistry and molecular biology [M]. Beijing: People's Health Publishing House, 2019:4.

[2] Li Cuiping, Zhang Wei, Zhao Chunpeng. Application of hierarchical teaching in experimental teaching of medical biochemistry and molecular biology ( $\mathrm{J}$ ) . Journal of science and education, 2015 (26): 121-122.

[3 Kang Xiangping, Zhang Xueli, Gong Zhangbin, et al. On biology from the perspective of "student centered"A preliminary study on the reform of chemistry teaching evaluation system [J]. TCM education, ECM, 2019,38 (5): 120-22.

[4] Li Dongping, Wang Rui, Li Xianmin. Teaching research and practice of mechanics of materials[J] Journal of Hebei University of Technology (SOCIAL SCIENCE EDITION), June, 2019.

[5] Ma Hongbo. Reflections on Project Teaching of basic statistical work in secondary vocational schools [J]. Accounting of township enterprises in China, 2020, 5.

[6] Chen Meihua. Experimental teaching quality evaluation method based on fuzzy comprehensive evaluation method [J]. Laboratory science, 2011,24. 
[7] Sang Shubing. Focus on smart classroom, feel the charm of mathematics J]. Scientific consultation (Teaching)Education and scientific research), 2020, 2.

[8] P. Xu; N. Na; S. Gao; C. Geng, Determination of sodium alginate in algae by near-infrared spectroscopy, Desalination and Water Treatment, 168(2019)117-122.

[9] P. Xu, N. Na, Study on Antibacterial Properties of Cellulose Acetate Seawater Desalination Reverse-Osmosis Membrane with Graphene Oxide, Journal of Coastal Research, 105(2020)246-251. 